\title{
Information and communication technologies and the role of consumers in innovation
}

\author{
Leslie Haddon
}

As a contribution to current discussions of the role of both actual consumers and representations of consumers in the innovation process, this chapter considers two empirical studies of the information and communication technology (ICT) industries. It asks:

1 To what extent, how and when are consumers (i.e. potential end users) considered or involved during the design of new products?

2 When consumers are actually involved in the process of innovation, what is the nature of their feedback?

3 Are some end users considered more than others?

4 What considerations and factors influence this overall pattern?

In addition, one development, relatively recent in some companies, has been the emergence of units whose role is to promote end users within the innovation process. So one extra question concerns:

5 Their success in meeting this goal and the factors which influence their efforts.

\section{Issues: users in design}

There is a growing literature referring to the importance of understanding and involving users in the design process in order to achieve successful innovations. In the field of industrial innovation, we find an early example of this argument illustrated by the role played by scientist 'users' working in universities on the development of scientific instruments (Von Hippel, 1976). In reviewing recent developments, Rip has observed that firms appear now to be taking more of an interest in these arguments about the need for greater user involvement (Rip, 1999) while Hoogma and Schot (1999, p. 2) note that this principle has also become increasing popular with governments. In fact, they cite an EC document lamenting the limited role still played by potential users. The following observations, drawn especially from some recent examples 
of writings on this theme, provide a background to the later discussion of ICT innovation.

Potential users of innovations may be spoken for or represented by others in the design process who may be outside the innovating firms. Examples would include parents, paediatricians and drug regulators speaking for children as the end consumers of certain types of new medical drugs (Rose, 1999), women's health advocates speaking for diverse contraceptive users (Van Kammen, 1999) and environmental groups speaking for people in general as regards any Green issues relating new innovations (Hoogma and Schot, 1999). In the case of ICT innovation, the second of the empirical studies to be discussed below, the role of such outsiders would appear to be more limited. Advocacy groups have had limited success overall, although some, such as those campaigning for disabled users, have achieved some influence in certain sectors ${ }^{1}$ (Haddon and Paul, 1999). Although they often limit intervention in consumer markets, governments can also represent end users by setting a framework for design. ${ }^{2}$

Those developing new innovations within the firm (or collaborating firms, or supporting agencies such as academic laboratories) also have images of users, their lifestyles and their 'needs'. A whole range of writings on technology, among other areas, have explored how these are socially constructed and mobilised, and how such assumptions are designed into innovations - for example, in the form of 'configuring the user' (Woolgar, 1991) or in the form of user 'scripts' which, when they are embodied in technologies, invite some practices and make others difficult (Akrich, 1992). What is of interest in this chapter, captured in the first empirical study, are the processes by which such representations emerge.

The same innovation may have different 'users': for example, in the medical field patients are in a sense one consumer of drugs, but clinicians also clearly use them (Van Kammen, 1999). In the case of the EFTPOS systems for using credit cards in supermarkets, both consumers and retailers count as different types of user of the service (Howells, 1999). Turning to the industry under examination in this chapter, while there are examples of ICT where users other than 'end users' are considered, in this industry it is more usually individuals or households which are the sole target, and that is the case in the empirical studies described below.

However, one observation of relevance to the later discussion of ICT is that the same innovation may have some initial users who may be in a position to help shape the product, but whose interests and relation to the technology may be different from later users'. In the field of industrial innovation these initial users, called 'lead users', have been characterised as providing more useful 'user feedback' by virtue of being more competent, resourceful and interested in innovation. The question then remains as to how well consumers can play this lead user role - Hoogma and Schot (1999) have some suggestions concerning what firms may have to do to create conditions favourable to the participation of such users in the innovation process. However, the 
problem remains that such initial users may not reflect the interests and perspectives, aspirations and orientation of potential later users. In the discussions of ICT innovation, the more common distinction is between 'early adopters' (such as technological enthusiasts) and various categories of later adopters.

One final discussion noted by several authors (described in Hoogma and Schot, 1999) concerns the important lessons which producers can learn by seeing what users do with their products, especially since some problems cannot be anticipated in advance. However, Hoogma and Schot also point to the limitations of this approach. Certainly innovators can learn about the effectiveness of a certain technology for achieving a particular goal. Hoogma and Schot $(1999$, p. 4) illustrate this by discussing how various demonstrations of electrical car experiments could show how users responded to particular features of the technology. They refer to it as 'single-loop learning'. In contrast, 'double-loop' learning would go a stage further to involve users in exploring and questioning the assumptions, values and world views which are built into innovations. The authors argue for giving users more chance to construct their own meanings and preferences during the innovation process and to be more active and creative, along with designers, in formulating new products which could satisfy their own needs. So rather than involving users late in the innovation process as 'a source of information about a preconceived product' (Hoogma and Schot, 1999, p. 3) there would be a process of 'mutual learning by both producers and users about the possibilities for use of the technology' (p. 2). Clearly one theme to be explored in relation to ICT is when and on what basis users are involved in providing feedback.

\section{Two empirical studies}

The first study ${ }^{3}$ of the shaping of information and communication technologies dealt principally with innovation initiated from and occurring within large companies (Cawson et al., 1995). It examined efforts, mainly but not solely in the United Kingdom, to develop consumer markets for home automation, ${ }^{4}$ interactive multimedia ${ }^{5}$ (mainly CD-i) and electronic messaging $^{6}$ (mainly e-mail). At the time of the study these were chosen as examples of fairly radical innovations in the consumer market: even by the end of the 1990s home automation has yet to be established; by the early 1990s CD-ROM technology had not yet led to the growth of multimedia PCs; and e-mail had not yet become widespread through the Internet. Part of the reason for the focus on radical innovations was that they posed particular problems for producers: there was no established market or widespread consumer base to refer to. ${ }^{7}$

The general aim of this first piece of research was to consider the innovation processes around domestic ICT (e.g. the origins of ideas, paths of development, etc.) but within the research one key question concerned the place of consumers. This relates to the above debates because it charted consumers' 
actual involvement in terms of giving feedback and the nature of that feedback, and what value innovators placed on such feedback. In addition, the study explored innovators' visions of consumers, and what other sources of knowledge about end users are taken into account (see also Miles et al., 1992). Hence these in-depth case studies explored the issue of where representations of users come from - and to some extent addressed the question why.

The second study ${ }^{8}$ covered a broad range of European ICT industries, ${ }^{9}$ dealing principally with innovation in the United Kingdom, Germany and the Netherlands, but with sub-studies in Italy, France, Spain and the Scandinavian countries (Van Dusseldorp et al., 1998; Haddon and Paul, 1999). Unlike the first study, the focus was not so much on specific innovations as case studies as on the processes of innovation within companies - although interviewees illustrated their points with specific examples. A second difference is that not all the innovations would necessarily be characterised as 'radical' in the same way that home automation, interactive multimedia and electronic messaging were at the time of that earlier research. For example, this second empirical study also included telephone handset and mobile phone design as well as services like home shopping. Internet access packages and web-site design. Finally, this second study examined a mixture of firms of different sizes ranging from large national and multinational to SMEs.

So from this second piece of research we have evidence concerning the role, timing and nature of consumer research in general from a far broader range of firms, both across Europe and in term of the types of ICT firms. Moreover, we can explore the question of what factors influenced decisions to involve users or what ones constrained their role in the design process. Also in this sample, and to an extent reflecting the change over time since the earlier study, we have a sub-sample of firms which could be considered 'leading-edge' in relation to this issue of involving end users. These companies had set up units within the firm (or sometimes employed individuals) specifically to take end users into account. So, as indicated in the introduction, we can ask questions about the situation of these user champions and the factors which have facilitated or inhibited their role.

\section{First study: ICT innovators' understanding of end users}

When we look at the whole process of innovation in the field of ICT, it could include such agents as the R\&D labs, marketing and advertising staff, agents who organise collaboration between firms, the industry process and distribution and retail staff. These agents can have slightly different representations, of both the potential consumer and the nature of the product, which can sometimes lead to conflict (Silverstone and Haddon, 1993). However, it would be true to say that in the case studies discussed below, and in many other examples of ICT development, product ideas, and hence early ideas about consumers and consumption, were mainly generated from and championed by technical staff in the R\&D labs. Hence they are the focus of attention in this analysis. 
To understand how consumers, or visions of consumers, are introduced into the design process, we need first to appreciate the origins of and stages in formulating innovative ideas. Although the marketing literature often talks about the pre-eminence of consumer demand, in the three areas studied producers clearly did not start with the questions of what people might need, what their interests were or what they currently desired. Rather, these producers were usually aware of technological possibilities, they were aware of their firm's competitive advantages and they searched for ways in which a technological opportunity or possibility might be turned into a product that might be adopted by consumers.

To illustrate this, let us consider an example relating to home automation. Here the initial technological potential was a home network containing a microprocessor and display system. This was then translated into a function which at least made sense in the home - displaying a message on the television that someone was ringing the doorbell. The innovators then tried to conceive of the conditions when this might be perceived as a benefit (e.g. for people with hearing impairments):

We had a lot of ribbing over this initially. But, amazingly, it's started to sell itself. Someone rings the front doorbell and the act of ringing the bell brings a legend on to the TV that says, 'Front doorbell ringing.' Now initially some people said, 'That's silly.' Except that, as other people quickly pointed out, an awful lot of people are hard of hearing or they are absorbed in the television. But then the message gives you the chance if you wish to press a button on your remote control handset and suddenly you can see that there's Auntie Mary come for cup of tea, or it's the insurance man, or it's someone you don't want to see. And if you're infirm or aged, that's useful. So, right away, something that started off along the lines 'Yes, we can do that. What use is it?' has developed into something that has an application for the two million hard-of-hearing or the so many million invalided.

This is actually the account provided by the type of agent who can often play a significant role in selecting from and developing product ideas: the product manager. Because of the pressure within these firms to consider consumers, such product managers, who usually but not always have a technical background, regularly differentiated themselves from the 'technical enthusiasts' in the labs. They often regarded the latter as having horizons which were limited because they thought mainly in engineering terms. Or else they sometimes regarded the ideas of 'techies' as being 'unrealistic', given the firm's previous experience of the market. Such product managers attempted to learn from past experience of 'the market'. This was part of the motive for some forms of intense producer interaction and pooling of ideas - clearest in the case of home automation, where such managers attended conferences and took part in EC-sponsored and other forums for some years.

In practice, both product managers and many of the other staff involved in the innovation process imagined how innovations might find a place in their own household - and how innovations might find a place among 
the interactions within their own (and sometimes their extended) family. In fact, this approach was more common than we had anticipated. The significance of this practice, as already noted in the earlier discussion of lead users and earlier adopters, is that the perspectives and preferences of innovators coming from certain social niches (in terms of class background and technical training) may be substantially different from those of later users of the new products.

Actual consumers played little part in the very early stages of product genesis. They were certainly not involved in a process of generating ICT product ideas - partly because product managers doubted that consumers might actually suggest radical product ideas which would in any way match the competences of the firms concerned. From the perspective of these managers, while consumers might state a desire for innovations which allowed them to avoid ironing, they were less likely, apart from technical hobbyists, to generate the idea of, for example, a Videotex system.

Moreover, in these studies consumers were usually not asked to evaluate the very early formulations of product ideas which were coming from the labs (i.e. concept testing) - or, if they were, in the form of focus groups, product managers were somewhat wary of interpreting the feedback. In fact, consumers tended to be involved later in such processes as product testing ${ }^{10}$ and evaluating interfaces.

Occasionally, consumers could play more of a role supplying feedback after the product was launched. For example, when the Micronet service was being developed on the Prestel Videotex system, one of the BT staff proposed the form of messaging now known as chat lines. He was allowed to design some software for the BBC computer and it was simply tried on-line, without further consumer research. As one of the Micronet staff commented:

This often happens. It's difficult to test a concept like chat lines, and the easiest thing to do, given you've got a user population as guinea pigs, and provided it's not costing you an arm and a leg to do it, is to just go at it that way. We as a central business decided we weren't going to develop it as a facility initially, we wanted it as a prototype. It was successful, it was very popular. So we decided to bring it on board.

And in fact, with a centralised service such as this one where it was relatively inexpensive to add a new feature, it was common to simply offer something and see how users responded - so, for example, MUD multi-user games were offered on the same basis. In fact, these Micronet users appear to have provided an unusual degree of feedback to British Telecom, compared with other types of on-line information system. Certainly a 'club' atmosphere was fostered, which was helped by the magazine component of the overall product and also by the hobbyist orientation of many consumers and staff:

It's always been foreseen that the users would determine the shape of the service by one means or another. In fact, they don't as much as we thought they 
would. Clearly they send messages to the editor and complain, and they are very vociferous about what they feel is important or not ... a very small number are, I should say. It's not quite as democratic as it might appear. But, yes, it was always envisaged that there would be a strong user feedback path. It was more like an on-line club. It was an electronic magazine for enthusiasts, written by enthusiasts.

The telling point here was that 'a small number' articulated their views. Although Micronet's audience may have been wider than technological hobbyists, the users volunteering feedback and potentially shaping development appear to have been the more technologically oriented.

It was noted earlier that product managers often felt that they were trying to be more sensitive to the market. So even if actual consumer research sometimes played a limited role, they were nevertheless trying to piece together evidence about consumers. Hence, within some firms, such product managers sought the views of outsiders, be it from marketing consultants or academics to supply information which they often felt they were lacking about the interests and behaviour of end users.

A more common process was to consider past markets. ${ }^{11}$ For example, at Philips, the staff who were developing CD- $i$ were dubious (like some other mainstream consumer electronics suppliers) about the 'success' of the early home computer market of the early to mid-1980s, seeing it as involving mainly hobbyists (and games players), and regarding the whole PC interface as being problematic for ordinary consumers. On the other hand, audio CD players, with their simple interface, were regarded as an example of a successful innovation. These two considerations shaped the decision about how CD- $i$ should be designed, with an interface more like a CD 'black box' and less like a PC (i.e. with no keyboard), hiding the technology, and stressing through marketing its ease of use and the software available. Meanwhile the growing ubiquity of remote controls (e.g. for television sets) led them to prefer this as the control interface - again, relying on evidence about what appeared to be popular and acceptable rather than actually seeking out consumer feedback.

Another approach involved monitoring trends. In the case of CD-i, Philips's US staff argued that there was a trend to more individual-centred activities which made the time ripe for their product - citing in evidence such factors as the fact that major mass television networks had lost audience, collective viewing within households had declined and the market for special-interest videos (e.g. fitness, gardening, sport) had grown.

So what emerges is a picture of innovators acting almost as detectives, using various sources of input to construct a view of family and social life. ${ }^{12}$ This process involved considerable interpretive work on the part of these producers, rather than simple observation - leaving scope for some of the disagreement over the scenarios which emerged. Nevertheless, these producers interacting as a 'community' at conferences, on committees and in other forums, could equally well reinforce each others' images of end users. 
On balance, these innovators paid far more attention to and made an effort to interact with other producers rather than investigating end users. While this reflected in part the uncertainties which innovators felt about consumer feedback, it also related to some of the realities of product launches. Other producers not only provided sources of judgements about the potential market and ideas about consumers but in those innovations involving collaboration (for example, in the case of home automation and CD-i) the support of the other producers was necessary literally to 'put the market together' - i.e. to create the conditions seen as necessary in order to give an innovation some chance of success with end users. Hence the importance of seeing what these co-producers of innovation thought, of sharing scenarios and sometimes of mutual persuasion that a market might exist. ${ }^{13}$

To summarise the findings in relation to the earlier discussion, we have seen a range of examples of how representations of users can be constructed from diverse sources. Some representations of users were specifically drawn upon because they could map on to what the technology might offer. Others came from producers' accumulated experience of markets, as well as their monitoring of a range of trends. In this whole process, at least in the case of products that were perceived as being more radical innovations, actual feedback from consumers played some, but a more limited, role compared with other inputs. In part, this reflected a degree of scepticism about what consumers might contribute to this type of innovation. Addressing the question of which consumers play a part in innovation, it was clear that some users rather than others were envisioned in this process ${ }^{14}$ (in the case of innovators thinking about their own or their families' circumstances) or else involved providing feedback (in the case of enthusiasts responding to innovations in Videotex). And in terms of the nature of this feedback, it would be more appropriate to characterise much of this user feedback as responding to product offerings.

\section{Second study: the role of end user research in the design process}

The most general result of this later and broader study was that the use of some consumer research during the innovation process was more common among larger companies, although by no means among all large companies. That said, larger companies were often composed of a range of different product development units, and within the same company some units were often more willing to seek consumer feedback than others. In contrast to the larger firms, though with exceptions, the smaller companies such as some software publishers and Internet designers were more likely to have very little or no user involvement.

Returning to the larger companies, the forms of user involvement which were now routine ${ }^{15}$ included (some) concept testing, prototype testing, usability testing, user trials and using software to monitor use. A few (though very few) companies went as far as to conduct surveys, hold focus groups or 
conduct in-depth interviews on topics which might provoke ideas about future products - which is the nearest they came to the principles of 'double loop' learning described in the earlier discussion. ${ }^{16}$

However, it must be added that while a majority of interviewees in the larger firms accepted the desirability of involving users at some point in the innovation process, some project managers still had reservations about the value of some of these exercises (e.g. owing to the perceived artificiality of trials and doubts, noted above in the first study, about the benefit of testing radical concepts on focus groups). So while firms may collect user feedback, how much weight they give to it can be a different matter.

Secondly, even among those which did collect information about users, some staff admitted that they were less successful than they would like to have been in actually integrating such data systematically into new product development.

In the face of general pressure to become more market-oriented, a variety of factors still operated to limit innovators' interest in consumer feedback. One was the general technology orientation of some companies, or parts of companies, although a number of larger firms were attempting to change the company culture in order to be more sensitive to the market. A second factor was the common attitude found among companies that 'success' measured simply in terms of increasing sales figures was sufficient to show that the products concerned met user demands. This was seen as being a good enough indication from 'the market' and justified little or no investment in customerrelated activities. A different reason for not involving actual end users in the design process emerged where firms believed that they already took users into account by virtue of following certain basic ergonomic principles such as making a commitment to simplicity, providing well structured information which was easy to access, being concerned about error-friendliness, allowing self-explanation, building in help functions, etc. If they already did all this, it was sometimes regarded as sufficient to meet anything the user might want from the innovation.

Undoubtedly the lack of time, especially, as well as lack of money, played a part. One reason for the limited role of users in the development process was the enormous time pressures experienced by many ICT firms to get their products quickly into a constantly changing market. While this may not be unique to ICT, that sense of urgency, because of fast-changing technology, is part of the culture of the industry. And even where user data were collected the same time and financial constraints limited how thoroughly the information could be analysed.

Outside any question of actual consumer research, there was also a problem of which consumers were considered by innovators. Certain interviewees noted that when staff did think of users, these (often) young designers who were at the cutting edge of innovation tended to think of users as being people 'like themselves': technophiles. In many cases the main target group for innovative solutions remained the trend-setting avant-garde for high-tech 
products. There appeared to be an underlying assumption that there is a 'trickle-down effect' whereby a product designed exclusively for this group would gradually become an everyday product for the majority of people. In other words, there was the problem of still considering initially just a narrow band of end users, not a mass market (and certainly not groups such as older and disabled consumers).

As regards the type of post-launch user feedback (and redesign) noted in the BT example above, obviously the scope for this itself depended on a variety of factors - for example, whether the firms concerned were dealing with the functionality of hardware, its industrial design, the core software architecture, more peripheral software that could be adapted, or content. So, for example, developers of interactive services, as in the Micronet example above, were in a better position to put their service on the market and then make alterations in the light of feedback once users were actually using the product. Some companies employed market research teams to phone up known users in order to get feedback for future product development. In fact, reviews of previous innovations, including evidence from users, sometimes had to take place because getting approval for future projects depended on whether past ones were considered to have been successful.

That said, a mixed picture of post-launch analysis emerges. One barrier to this process, noted by innovators in small but also in larger firms, was that staff were sometimes reluctant to conduct post-launch research because they had already used up their budget in the course of getting the product to market and they had not made provision for adaptations in the light of user feedback. As noted above, others felt that they were not capable of handling the user feedback which they routinely collected about the products they had already brought to market. And in some cases the feedback was never analysed because the staff involved in the initial innovation had moved on to other projects within the company.

Lastly, we have the consequences of collaboration between firms. First, there was, to various degrees, formal or informal collaboration between larger companies with complementary assets, e.g. the network operators of various sorts who maintain a channel, be it the phone, the Internet or television, the service or content providers who use that channel, and the hardware companies that support the whole operation. To the extent that they did not compete, some of these (such as telecom operators and telephone hardware suppliers) met regularly to share their scenarios, visions of users and sometimes even the evidence from consumers which they had collected. This could be a particularly important source of information about consumers for firms relatively upstream in the innovation process - e.g. the chip makers who supplied telephone or consumer electronics manufacturers and who did not themselves have any direct linkage with end users.

The other common form of collaboration involved one firm setting up a technology or service on behalf of a client, perhaps later handing over responsibility for maintenance and development to that client. Examples 
would include the software developed for home shopping services or for PC banking. In fact, some of the technical or service suppliers in the study reported that as companies they themselves had had to change over time, putting more emphasis on understanding not only their clients but their clients' customers, and for this they relied on information being passed on to them. ${ }^{17}$ To some extent clients' knowledge of users was fed back into the development process or fed back to these more technical staff - although it was equally clear that some such knowledge was also either withheld or the need to pass it on was somehow overlooked.

But it is when the above form of collaboration involved smaller SMEs supplying the technical expertise that the issue of client feedback about end users became more crucial. This was because with their limited resources such SMEs were often not in a strong position to gather their own information about end users. However, in many cases, the commissioning clients failed in this respect: even when they had information about users, the data were not fed back to the outside designers. Sometimes the client even failed to take a strong lead in defining the end user, relying on the SMEs to do so. Hence there was some uncertainty in projects in which design was partly outsourced. Moreover, the problem of who took responsibility for defining and elaborating the picture of the end user was sometimes made even more difficult when there was not just a single client-supplier relationship but a whole network of small partners involved.

In sum, the findings from this wider sample suggested that the practice of expecting to get some form of user feedback was not common in larger firms, although not in all large firms or in all parts of larger firms. This broader study again drew attention to some of the concerns about the usefulness of consumer feedback, more so with radical innovation and the fact that some users, in effect 'early adopters', tended to be considered more than others. ${ }^{18}$ The degree to which post-launch analysis of user feedback takes place was uneven, although this could in part reflect the nature of the product. When a variety of producers collaborated, in general or in relation to a particular innovation, there was an important process of sharing both representations of users and evidence about them - but sometimes the sharing was more limited than some partners would desire, more clearly so in the case of SMEs. And, as in the previous study, it would be more appropriate to characterise much of the user feedback as reacting to product offerings, although there were a few examples of practices that attempted to evoke feedback which might stimulate product ideas.

\section{Third study: the experience of units specialising in end users}

These units included market research groups, human factor departments (much more rarely) ageing and disability units and other R\&D groups going by various names which had often employed social scientists. This was perhaps most striking in the telecom sector, where a range of operators, but also 
the hardware companies supplying them, had employed such staff on the grounds that companies felt that they were too technology-oriented and needed to know their markets better with the move to privatisation. ${ }^{19}$ While some of the work of these units involved users in evaluating preconceived products, this was also the location where one was more likely to find research ${ }^{20}$ exploring consumers' lives and views. It was some of these units which were involved in concept testing.

However, the context in which they operated was one where the larger companies often consisted of fairly autonomous business units which acted as their own profit centres or else they had subsidiaries which operated fairly independently. So while the parent company might have set up the various units within the whole organisation to think about end users, there was often no requirement for the separate business units to consult any of them. Hence, while good rapport had been established with some business units which valued the input about consumers, other business units did not make use of the services of these user champions. Indeed, sometimes business units preferred to assemble their own team to think about the market. Where such product development groups were composed solely of technical staff working in isolation from the rest of the company, they could operate with more limited horizons concerning what users were like and remained unreceptive to new forms of, especially empirical, input.

Clearly the place in the design process of the social science staff and others specialising in end users could be problematic. To be fair, these staff often felt that they were having at least some success in raising awareness of end users and making others in the company take on a wider range of social considerations. Insights about users from these staff were sometimes taken up by those technical innovators who were more sympathetic to that input. But, as noted above, in other parts of the companies they either met with more resistance or were ignored - or else, in really large companies, their existence was still unknown in some quarters in spite of efforts to publicise their services.

Sometimes there were communication problems: the technical designer and social scientist communities were often separated, sometimes geographically, but also within the organisational structure (e.g. being connected only by intermediary product managers). In this respect, a number of interviewees identified one of the more promising practices of forming interdisciplinary teams to consider new product development. Here staff from these units (or individual social science staff 'representing' end-user perspectives) could negotiate with others from $R \& D$. In such circumstances the user champions were seen less as outsiders, and in the process of talking directly with others in the team they could provoke technical staff to think about a wider range of considerations than they might otherwise have done.

However, when the two sides rarely met, some of the technical staff did not appreciate (or in some cases understand) some of the potential contribution from these units, more so when they came from social scientists with an academic background. The innovators did not see how it was relevant for the 
type of design decisions they wanted to make. Meanwhile, some of these same social scientists acknowledged that they sometimes did not know exactly what the technical staff wanted. At times the different styles of language used by the two communities could also lead to communication problems. ${ }^{21}$

Finally, whether in relation to technical or marketing staff, some of these units specialising in end users were also under pressure to prove that any suggestions they made would be profitable. This was not always straightforward, especially when there were other criteria that could be applied, such as the principle that certain changes in design would lead to a 'better' product, more usable by more people. The inherent difficulty of precisely quantifying benefits could sometimes be used as a rationale for excluding those units from the innovation process.

Before drawing together some of the above observations, it is worth restating the point that the role and experiences of units within larger firms which specialise in representing (as well as researching) end-user perspectives have been less discussed in the above literature and in some companies are a relatively new phenomenon. The above research showed that while much of their empirical input involved eliciting consumer responses to products and product concepts, other research provided new kinds of exploratory feedback with the potential to be an input to new product innovation. However, the experience of these units was also mixed, even when dealing with different parts of the same firm. Sometimes they felt that they were being more successful in getting technical innovators to consider a wider range of factors about end users (or particular users such as the elderly and disabled). At other times, a range of factors outlined above militated against their influence.

\section{Conclusion}

While innovators have representations of and knowledge about consumers, actual consumer input into the design process is only one source among others of their understanding of potential consumption. The two studies are not strictly comparable so we cannot say whether that consumer input has increased over time. However, the ongoing discussions within at least parts of the ICT industry about the need to be sensitive to the market and the establishment of units to promote consideration of users within some sectors suggest that a degree of consumer consultation may have become more standard practice within at least some of the larger firms - and that was also the impression which many interviewees gave in the second study.

That said, this chapter has explored a number of constraints working against involving potential end users in the innovation process, and even where feedback is collected there is no guarantee that it will be used or of the weighting it will have among other considerations. In the case of what are perceived as more radical innovations, feedback can often take place relatively late in the whole process, although in some firms there is now more involvement of consumers at the conceptual stages. Given that many product ideas stem from 
awareness of technological possibilities, consumers' feedback is more usually in the form of reaction to product proposals rather than generating them. Through a variety of mechanisms outlined above, some consumers are often considered more than others in this whole design process.

Lastly, the employment of end-user champions has gone some way to help widen the degree to which consumers are considered and the ways in which they are taken into account. Yet the process remains uneven, and there are still factors relating to the culture of firms and their organisation which can make the role of these units problematic. Of course, taking a more critical note, such user champions themselves translate what any user feedback means within the firm and they 'represent' consumers, or groups of consumers, just as agents outside the firm do. As such, their own interpretations could themselves be the subject of analysis. But if the starting point of this chapter was the literature suggesting more interest in consumer involvement in innovation, then in the ICT industry such units are trying to raise the user profile and in many cases they are helping to introduce more user feedback into the design process.

\section{Notes}

1 For example, the Royal National Institute commissioned designs of fonts for television screens which were easier to read than existing ones. Philips has not introduced these fonts into its chip set for the next generation of teletext.

2 For instance, the strict legal requirements for ATM design in North America which takes disabled users into account has influenced the design of the cash points available in Europe.

3 'Delivering IT into the Home' was a study sponsored by the ESRC and lasted from 1988 to 1990.

4 This refers to integrated systems of consumer ICT products known variously as 'smart houses' or 'intelligent home' systems, 'interactive home systems', 'home networks', 'domotique', 'batimation', etc. The challenge for suppliers here was to produce a viable mode of integrating various ICT products and providing control systems for such products.

5 This refers to the use of optical disc technology to deliver varied forms of information (text, graphics, video) in new, more interactive ways. The focus of the study was on CD- $i$ but other competing formats were considered.

6 This focused mainly on electronic mail and Videotex services aimed at consumer markets, but also covered functional alternatives such as home facsimile machines.

7 The same point and the difficulties it raises have been discussed in relation to radical medical innovations (Martin, 1999, p. 2).

8 'Design for All and ICT Business Practice: addressing the barriers' was sponsored by the European Union's DG XIII TIDE programme and was conducted in 1998. TIDE, focusing on the potential role of ICT for disabled and elderly people, wished to promote Design for All/Inclusive Design (e.g. via standard setting, promoting best practice, etc.). It commissioned this study to consider how much elderly and disabled users were considered in the design processes of ICT companies, 
but as a prior step the researchers tried to ascertain the extent to which and the ways in which consumers in general were taken into account.

9 This included telecom operators and their hardware suppliers, ICT innovation within the transport industry, public information services, software publishers, the Internet industry, broadcasters, suppliers of interactive services and firms involved in electronic commerce and financial services.

10 For example, US focus groups monitored reactions to CD- $i$ when it was nearly ready for launch and when price information was available.

11 This was also noted in the case of radical innovations in medicine, where innovators drew on the commercialisation history of previous medical products when planning new innovations (Martin, 1999, p. 13).

12 In consumer markets this is largely so because what is happening in households is in some senses far less directly visible to innovators than, say, the operation of a client organisation where the innovators could attempt to go in and map the 'needs' of the client and the organisational processes at work.

13 Although, after many years, this clearly failed in the case of home automation when no one was prepared to take the risk of being a first mover.

14 Feminists have also drawn attention to the way male technical staff produce products that they think will interest other males - including home automation functions (Berg, 1990). Meanwhile, Wajcman notes, 'the designers of domestic technology have so far been subjected to very little investigation; an examination of their backgrounds, interests and motivation may shed light on the development of particular products' (Wajcman, 1991, p. 106).

15 This was occasionally even stipulated in the firms' checklists of actions to be undertaken at different stages in the innovation process.

16 Such consumer feedback was also sought in focus group discussions, among other types of information about daily life, as part of pre-competitive research conducted jointly by European telecom companies (the EURESCOM P-903 project, of which the author was a subcontracted participant).

17 In addition, larger suppliers had themselves sometimes built up a certain knowledge of end users from previous projects. In fact, there was one instance where it was actually the technical suppler which had 'accessibility' issues on its design checklist - which the supplier then raised with its client.

18 Also, elderly and disabled users were only rarely considered (Haddon and Paul, 1999).

19 The results of this process for ageing and disability units was uneven: for example, in the UK British Telecom's unit has remained influential for some years, while in some of the Scandinavian telecom operators such units have declined or faced problems as firms have emphasised the 'mass market'.

20 As an illustration, many of the social scientist staff from within European telecom companies were involved in COST 248 and later COST 269 programmes - where they met, along with academics, to discuss future users and share some of their empirical research. Examples would be the Future European Telecommunications User Home and Work Group (1997) and Haddon (1997).

21 In companies which were arguably more market-driven, it was sometimes the decision-making marketing staff who were not interested in any findings about users if they regarded the results and implications as being too complex (e.g. if they did not produce market segments which fitted into existing marketing categories). 


\section{References}

Akrich, M. (1992), 'The de-scription of technical objects', in Bijker, W., and Law, J. (eds), Shaping Technology/Building Society: studies in sociotechnical change, Cambridge MA, MIT Press.

Berg, A. (1990), 'He, she and IT: designing the home of the future', in Sorensen, K., and Berg, A. (eds), Technology and Everyday Life: trajectories and transformations, Report No. 5, Oslo, Norwegian Research Council for Science and Humanities.

Cawson, A., Haddon, L., and Miles, I. (1995), The Shape of Things to Consume: bringing information technology into the home, Aldershot, Avebury.

Future European Telecommunications User Home and Work Group (1997), Blurring Boundaries: when are information and communication technologies coming home? COST 248 report, Farsta, Telia.

Haddon, L., ed. (1997), Communications on the Move: the experience of mobile telephony in the 1990s, COST 248 report, Farsta, Telia.

Haddon, L., and Paul, G. (1999), 'Design in the ICT Industry: the role of users', paper for the fifth ASEAT conference, 'Demand, Markets, Users and Innovation: sociological and economic approaches', 14-16 September, Manchester, UMIST.

Hoogma, R., and Schot, J. (1999), 'How Innovative are Users? A critique of learningby-doing-and-using', paper for the fifth ASEAT conference, 'Demand, Markets, Users and Innovation: sociological and economic approaches', 14-16 September, Manchester, UMIST.

Howells, J. (1999), 'Rethinking the Market-Technology Relationship for Innovation', paper for the fifth ASEAT conference, 'Demand, Markets, Users and Innovation: sociological and economic approaches', 14-16 September, Manchester, UMIST.

Martin, P. (1999), 'Great Expectations: the construction of markets, products and user needs during the early development of gene therapy in the USA', paper for the fifth ASEAT conference, 'Demand, Markets, Users and Innovation: sociological and economic approaches', 14-16 September, Manchester, UMIST.

Miles, I., Cawson, A., and Haddon, L. (1992), 'The shape of things to consume', in Silverstone, R., and Hirsch, E. (eds), Consuming Technologies: media and information in domestic spaces, London, Routledge.

Rip, A. (1999), Keynote address, fifth ASEAT conference, 'Demand, Markets, Users and Innovation: sociological and economic approaches', 14-16 September, Manchester, UMIST.

Rose, D. (1999), 'Reconceptualizing the user(s) of - and in - Technological Innovation: the case of vaccines in the US', paper for the fifth ASEAT conference, 'Demand, Markets, Users and Innovation: sociological and economic approaches, 14-16 September, Manchester, UMIST.

Silverstone, R., and Haddon, L. (1993), Future Compatible? Information and communication technologies in the home. A methodology and a case study, report for RACE Project 2086, Falmer, University of Sussex.

Silverstone, R., and Haddon, L. (1996), 'Design and the domestication of information and communication technologies: technical change and everyday life', in Silverstone, R., and Mansell, R. (eds), Communication by Design: the politics of information and communication technologies, Oxford, Oxford University Press.

Van Dusseldorp, M., Haddon, L., and Paul, G. (1998), Design for All and ICT Business Practice, report for TIDE, Delft, TNO. 
Van Kammen, J. (1999), 'Users’ Involvement in Contraceptive Innovation: the design of anti-fertility vaccines', paper for the fifth ASEAT conference, 'Demand, Markets, Users and Innovation: sociological and economic approaches' 14-16 September, Manchester, UMIST.

Von Hippel, E. (1976), 'The dominant role of users in the scientific instrument innovation process', Research Policy, 5, pp. 212-39.

Wajcman, J. (1991), Feminism Confronts Technology, London, Polity Press.

Woolgar, S. (1991), 'Configuring the user: the case of usability trials', in Law, J. (ed.), A Sociology of Monsters, London, Routledge. 